\title{
O VAZIO E O MOVIMENTO
}

\section{EMPTINESS AND MOVEMENT}

\author{
EL VACÍO Y EL MOVIMIENTO
}

Ana Godinho Gil ${ }^{1}$

\section{RESUMO}

No cruzamento entre a filosofia e as artes em geral surge um espaço de experimentação singular e dele surge uma multiplicidade de problemáticas a partir das quais formularemos duas questões: o que move um corpo? Como se forma uma forma? Referir-nos-emos a condições e procedimentos envolvidos na produção dos corpos e do vazio, tomando o vazio e depois o ritmo como condição do movimento. Ambos, ligados entre si, produzirão um sopro que, por sua vez, liga todas as coisas. Procuraremos ver como a ideia de "lugar funcional" vai muito para lá do dizível e do pensável, constituindo-se como meio de transporte e de captura das forças. O sopro, o vazio e o ritmo, enquanto potências imperceptíveis, contribuirão na nossa análise para se compreender o que é um corpo em devir capaz de mil metamorfoses.

PALAVRAS-CHAVE: Corpo. Vazio. Movimento. Força. Forma.

\section{ABSTRACT}

At the intersection between philosophy and the arts in general, a space of singular experimentation arises and from it arises a multiplicity of problems from which we will ask two questions: what moves a body? How to form a shape? We will refer to conditions and procedures involved in the production of bodies and emptiness by taking emptiness and then rhythm as a condition of movement. Both, linked together, will produce a breath that in turn binds all things together. We will try to see how the idea of a "functional place" goes far beyond the sayable and the thinkable, constituting itself as a means of transport and capture of forces. The breath, emptiness and rhythm, as imperceptible powers, will contribute in our analysis to understand what a body is in becoming capable of a thousand metamorphoses.

KEYWORDS: Body. Emptiness. Movement. Force. Shape.

\section{RESUMEN}

En el cruce entre la filosofía y las artes en general surge un espacio de experimentación singular y de él surge una multiplicidad de problemáticas a partir de las cuales formularemos dos cuestiones: ¿qué mueve un cuerpo? ¿Cómo se forma una forma? Nos referiremos a condiciones y procedimientos implicados en la producción de los cuerpos y del vacío tomando el vacío y luego el ritmo como condición del movimiento. Ambos, unidos entre sí, producirán un soplo que a su vez conecta todas las cosas. Buscaremos ver cómo la idea de "lugar funcional" va mucho más allá de lo decente y de lo pensable, constituyéndose como medio de transporte y de captura de las fuerzas. El soplo, el vacío y el ritmo, como potencias imperceptibles, contribuirán en nuestro análisis para comprender lo que es un cuerpo en el devenir capaz de mil metamorfosis.

\footnotetext{
${ }^{1}$ Doutora em Filosofia da Linguagem - Faculdade de Ciências Sociais e Humanas - Universidade NOVA de Lisboa (FCSH / UNL) - Lisboa, Portugal. Professor Assistente Convidado - Universidade de Évora (UEVORA) - Évora, Portugal.Professor Assistente Convidado (2007-2008) - Faculdade de Arquitetura / UTL - Lisboa, Portugal.

E-mail: anagodinhogil@sapo.pt

Submetido em: 28/02/2019 - Aceito em: 04/09/2019
}

(C) ETD-Educação Temática Digital Campinas, SP $\quad$ v.21 n.4 $\quad$ p.847-856 $\quad$ out./dez. 2019 
PALAVRAS-CLAVE: Cuerpo. Vacío. Movimiento. Fuerza. Forma

\section{O VAZIO E O MOVIMENTO}

Um corpo forma-se e não cessa de se formar, transformar ou de-formar, metamorfosear-se. O que move um corpo? Ou o que move a mão e o pensamento? Como libertar o corpo e a mão? De que corpo falamos?

Do corpo na arte, dos corpos que os artistas fazem, um poema, um desenho, uma música, uma dança, uma tela?

Referir-nos-emos a condições e procedimentos envolvidos na produção destes corpos e a um em particular - a produção de vazio.

Diante da tela branca, Francis Bacon limpa, escova, esfrega. Movimentos motores aparentemente simples encadeiam-se com movimentos invisíveis, sairá qualquer coisa juntamente com eles. Bacon elimina da tela o que o ameaça e ameaça a sua pintura (como o pintor, o escritor tem muitas coisas na cabeça, à sua volta). Trata-se de um processo de produção de vazio. É um procedimento fundamental.

O cheiro da tela branca ou do papel tem de desaparecer para dar lugar ao plenamente vazio. O vazio é condição do movimento e este é forma em devir. Quando o vazio se abre, fabrica-se um outro espaço, e dele libertar-se-á um corpo. E esse corpo será fonte do movimento como "um vazio ou uma elipse que faz com que se contorne uma constante sem se comprometer, ou que a abordamos por baixo ou por cima sem nela nos instalarmos" (DELEUZE, 1980, p. 132).

Nesse vazio, aberto, zona "funcional", "zona de indiscernibilidade" entre um homem e um animal, entre um corpo e a paisagem ou entre as árvores e as montanhas, entre dois átomos, há uma zona comum quase igual a um nada, que aparece sem referência, desigual, sem identificação possível, limpa de quaisquer associações. É um qualquer coisa a tornar-se outra coisa, um devir. Que não se pode ver como uma combinação de formas que preenchem um espaço dado, não são correspondências formais que se possam tecer a partir de alguma coisa, é antes a constituição de um espaço-tempo por vir, um vazio mesmo. Há que avançar até aí, diz Deleuze, avançar até onde, de súbito, possa reinar uma Justiça que não será senão Cor ou luz, um espaço que não será senão um Saara.

É “como se de súbito se introduzisse um Saara, uma zona de Saara, na cabeça; é como

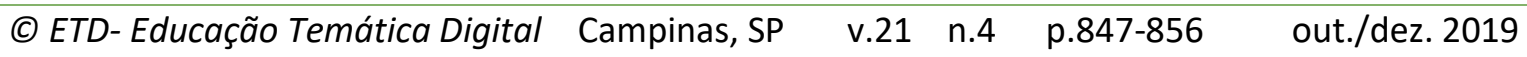


se nela se esticasse uma pele de rinoceronte vista ao microscópio; é como se se separassem duas partes da cabeça pondo um oceano no meio; é como se se mudasse de unidade de medida e se substituíssem as unidades figurativas por unidades micrométricas ou, pelo contrário, cósmicas. Um Saara... é assim o diagrama de súbito estendido" (DELEUZE, 2011, p. 170).

Uma espécie de vontade de devir, uma vontade de vazio, que não é um aniquilamento, faz o artista, o pensador, o escritor entrar num ritmo, numa coexistência de todos os movimentos. O vazio é então povoado. E o devir é o movimento-força que, como uma explosão, torna o vazio num lugar de metamorfoses. O que é uma vontade de devir? Ou uma força? É o momento mesmo da produção de vazio, o instante mesmo do desejo de vazio. Uma espécie de acção mágica que muda sem cessar os corpos e as vidas. A força encontra o vazio em que ela existe como movimento e, nesse encontro, forças e corpos são o motivo, uma espécie de razão sem nenhuma falta. Tudo na natureza se move e o movimento é uma indicação primeira de vida. Espécie de mantiké/enthousiasmos, "acto livre" da alma, que manipula certos objectos para extrair deles uma presença, um acontecimento que traz o futuro. "O movimento faz-se sempre no intervalo entre os dois, nas vossas costas" (DELEUZE, 1983, p. 9) e acontece num "tempo menor do que o mínimo de tempo contínuo pensável", passagem ultra-rápida entre linhas de um ponto ao outro.

O corpo, no espaço que ele cria, é o lugar do seu acontecimento. É no próprio corpo que nasce o desejo de espaço, que se transformará em vazio. O corpo, "linha abstrata" que, como uma flecha, atravessa o próprio vazio, e nele se moverá, é o seu próprio motivo. Materiais heterogéneos, tensões várias, direcções contrárias criam-se e sustentam-se de forma singular no vazio. As forças estão em todos os lados e em todos os lugares. Todo o problema é captá-las ou dissolvê-las e conservá-las o quanto é necessário.

Onde se pode fazer ouvir o tempo? Onde se pode pintar um grito? Como se tornam visíveis as forças de enrugamento das montanhas? A força de germinação de uma maçã onde está? Onde está a força térmica (o "calor do vazio", a que Deleuze e Guattari se referem) de uma paisagem?

O vazio será então "o lugar funcional", meio de transporte e de captura das forças. 0 vazio no interior dos próprios corpos, levando mais longe a noção, corresponderia a uma espécie de "vácuo quântico", onde partículas de força virtuais, em campos eletromagnéticos e gravitacionais, interagem entre si com uma quantidade mínima de energia.

O devir-vazio define-se como um jogo ideal, jogo de um só lance, que desencadeia e

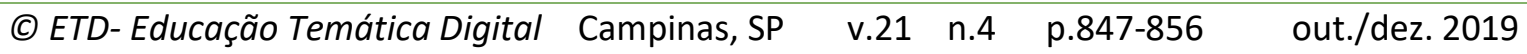


liberta forças, modulando-as. Os corpos apanhados neste meio - vazio-ritmo - preservamnas, ou conservam-nas e agem, produzindo efeitos desde o começo dos tempos. Efeitos que constituem os acontecimentos do mundo. "A história do mundo data do dia em que dois átomos se encontraram, em que dois turbilhões, duas danças químicas se combinaram" (DORAN, 1978, p. 112). São forças ou partículas que estão já lá, desde o começo, encontramse num único instante antes de qualquer coisa, paradoxalmente presentes e sempre ausentes como o próprio vazio. E faz-se caos ou vazio para se capturar o ritmo, para conservar a mudança incessantemente criadora do espaço e do tempo.

O vazio aparece então, de acordo com F. Cheng (1979), como o "lugar funcional onde se opera a transformação" (p. 32) ou, de acordo com Maldiney (1973), como o "acto pelo qual uma forma se forma" (p. 161). O vazio, incorporal, segundo Sexto Empírico (Bréhier, 1997, p. 12), não é parte do mundo, mas algo que, "associado e fora", é condição do movimento. Fora dos limites do mundo, é sem limite, sem coordenadas: mas "lugar funcional onde se opera a transformação". E escapa-nos sempre.

Não sabemos de que natureza é este vazio. Podemos tomá-lo como um incorpóreo. Impensável, Aiôn, elemento paradoxal, ponto aleatório sempre deslocado, puro instante da disjunção. $O$ que escapa às coordenadas ou está fora dos limites do mundo é um ainda-por vir-e-já-presente. Separado dos corpos, não há nada nele, nenhuma diferença, nenhuma repetição. Também podemos dizer que ele não é um nada do qual não há nada a retirar. Mas ele está sempre aí onde menos o esperamos, ele é a natureza comum a todos os seres. "É o instante sem espessura e sem extensão que subdivide cada presente em passado e futuro, em lugar de presentes vastos e espessos que compreendem, uns em relação aos outros, 0 futuro e o passado" (DELEUZE, 1969, p. 193).

E, mesmo se é impróprio dizê-lo, porque não se fabrica o vazio, a verdade é que Bacon ou Cézanne e muitos outros o produzem. Fazer vazio para se poder fazer um corpo. O vazio é então condição do movimento e dos corpos. Se ele é aquele onde a forma se forma, dele sairão devires, multiplicidades, ubiquidades, metamorfoses, seres desiguais, desterritórios, materiais onde o tempo e espaço se incorporaram, transformando-se. Os corpos precisam essencialmente de vazio, como precisam de silêncio, de vazios intervalares, de poros, de telas virgens. Mil acontecimentos, num entre, produzem corpos e estes corpos são finalmente corpos não triviais que escapam ao transitório, aos clichês e às crueldades.

Como produzir um corpo assim? Um corpo-acontecimento, aquele que nunca morre, sempre vivo e onde coexistem todos os tempos e espaços em movimento?

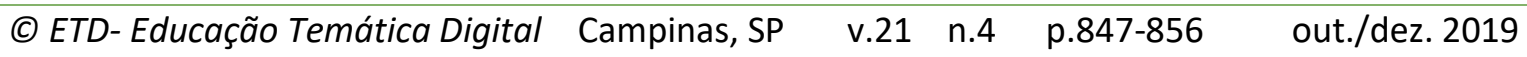


Dos seis princípios da pintura chinesa, enunciados por Sie-Ho, de que Maldiney cita apenas os dois primeiros, retiremos o essencial: é preciso que o pintor seja capaz de apanhar a vitalidade imanente, o "sopro vital", esse que é vazio rítmico e que faz subsistir um corpo ainda "quase-nada". Quer dizer, o sopro vital que se exprime e cria o movimento da vida. 0 pintor é, então, nesse instante, criador de movimento, "procura a ossatura" (MALDINEY, 1973, p. 167).

Se o pintor apanha ou captura estes princípios e os modos da sua realização, impregna todas as coisas numa só, numa linha, numa cor, num contorno. Reúne-as num todo, porque entra num devir-pintura e pode assim "respirar a virgindade do mundo" (DORAN, 1978, p. 112). Nesse momento em que ele e o quadro são um, todas as cores do arco-íris se encontram num caos irisado.

Como pintar um peixe sem descobrir a linha serpenteante do universo que o une à pedra que ele toca no fundo do rio e às ervas da margem em que ele se dissimula? Como pintá-lo sem o animar com o sopro cósmico do qual ele não é senão um elo?

Yu T’ang, pintor dos Song, diz num texto: "Para pintar um peixe, é preciso que o artista conheça a 'natureza' do peixe; mas para aí chegar, o pintor deve, utilizando a sua intuição, acompanhar o peixe quando ele nada, em espírito, partilhar as suas reacções às correntes, às tempestades, ao sol, aos engodos. Só um artista que compreenda as alegrias e as emoções de um salmão a atravessar um rápido tem o direito de pintar um salmão, senão deixe-o tranquilo. Pois por muito preciso que seja o seu desenho das escamas, das barbatanas e das pálpebras, o conjunto parecerá morto" (apud MALDINEY, 1973, p. 168).

O pintor deve "ver" a natureza do peixe, descobrir em que momento essas relações se ligam à sua própria natureza. Haverá então um olho e uma mão que ligam, num instante qualquer, certas partes do mundo a outras como quem liga partes do mundo ao infinito (no caso do pássaro de Bacon), como Bacon refere em Pintura (1946), em que só Ihe interessava "fazer uma ave no momento de pousar num campo" (DELEUZE, 2011, p. 257). Quer dizer, sonhava compor no vazio conservando a natureza do pássaro. Mas fica sempre um elo em falta, na cadeia que vai da intenção à realização. É necessário "saber" capturar e produzir o vazio.

Fora dos eixos habituais, que preenchem o espaço inteiro, apanhando o vazio-ritmo, podem produzir-se os corpos vivos, as cores, os traços, as palavras, os sons. Numa palavra, 
encontrou-se a zona "funcional" onde "o nosso cérebro e o universo se encontram" (DORAN, 1978, p. 112). A oportunidade que dá lugar ao ritmo, o começo paradoxal, está no próprio vazio e no próprio ritmo. Em qualquer situação, diz Maldiney (1973), podem ambos coexistir e fazê-lo com todos os movimentos que capturam a vitalidade, o sopro que é vida orgânica e inorgânica. O sopro mais real, em contacto directo, sem quaisquer mediações, "anima" o mundo todo, num instante. Podemos ainda dar-lhe outros nomes: ar, respiração, espírito, pneuma...

Se do vazio e do ritmo ligados entre si sai o sopro, é o sopro que exige o vazio, porque é ele que une todas as coisas. O sopro é então o lugar comum, potência imperceptível, entre o indivíduo e o universo.

Como se forma uma forma? Uma forma na sua absoluta singularidade e inteira independência?

Sai do vazio ou do nada? Sai de um indiferenciado virtual, de um caos, um abismo. 0 vazio pensado enquanto abertura paradoxal: o vazio é o vazio. Abrir-se ao vazio é o procedimento, modo de realização, capaz de pôr "um oceano no meio" para poder habitar plenamente a pintura, a poesia, a música, o pensamento.

Reconhecemos forças "espirituais", diz Freud; mesmo que as não possamos ver, sabemos dos seus efeitos. O "ar em movimento", o sopro, descobrem essas forças espirituais nos corpos. Corpos "quase nada" que preservam uma vitalidade imanente, que é a vida. 0 sopro é muito real. Anaxímenes usou-o como unificador do cosmos. Para os pitagóricos, o ar e a respiração, juntamente com o vazio, são inalados pelo universo.

A respiração é sopro e funde-se com o vazio e o espírito. Está, pois, ligada ao princípio vital. O ar quente dentro de nós, o "calor do vazio", é "a alma" que circula pelo corpo à volta dele. Respira-se ar, inala-se o vazio todo, sopra-se para fora. As forças haverão de ressoar e produzir os seus efeitos fortíssimos, dirá, também, Freud.

Procedimentos como atenção e observação (por exemplo, do movimento de inspiração-expiração em práticas como o ioga ou a meditação Zen), em situações muito específicas, exigem ao corpo um movimento mínimo, infra-fino, subtil, e levam-no para estados intervalares próximos desse vazio. O espírito ou alma concentra-se e faz um só, com o sopro, o movimento e o vazio.

Apreendeu-se em espírito a natureza e pode então dançar-se, pensar, pintar, escrever ou só ficar sentado. Os movimentos rítmicos imperceptíveis, e o vazio produzido, afastam o

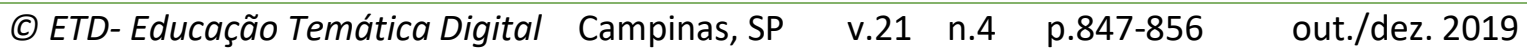


ruído exterior, os impasses vários, anulam a distracção, as "nuvens". O ar em movimento flui e apanha o curso natural dos acontecimentos, a vida original. É um modo de viver, animado, presença viva que a cada instante porfia e desembaraça o fio contínuo e sem fim do tempo e do espaço banais. Fica-se necessariamente com outro corpo. "O [que] tem de mergulhar para alcançar o impensado, isto é, a vida. Não que o corpo pense, mas obstinado, teimoso, força a pensar e força a pensar o que se esquiva ao pensamento, a vida" (DELEUZE, 1983, p. 243).

om que corpo se fica? A supor que não há um antes e um depois, que se começa infinitamente, se compõe e decompõe e se é incapaz de dizer por onde começa, é um corpo inintencional, em transformação. Só uma respiração que se move para cima e para baixo, em mil direç̧ões, entre o quente e o frio, para fora e para dentro, é capaz de todas suspensões e pausas. Vira-se e volta-se, enrola-se e fecha-se. Ganha asas e cai, sobe, inclina-se e expandese. Desorienta-se e perde-se, orienta-se e perde-se, deixa-se levar e parte, fica imóvel. Corpo sem eixos, virado do avesso, que não podemos alcançar com os sentidos habituais. Por onde começa o corpo? Começa sem começar pela parte mais viva que o liga à vacuidade do mundo.

Um corpo, verdadeiramente vazio, capaz de mil metamorfoses (corpo paisagem, árvore, montanha e céu), corpo-mundo a caminhar sem trilhos, sem fazer caminho ao andar (porque não deixa pisadas), corpo plenamente atento a cada ínfimo momento, um corpo-espírito como o do bailarino quando dança ou o do pintor quando pinta. O ar em movimento, que o atravessa e o envolve, torna-o impenetrável, invulnerável. Torna-se o corpo que

\section{viaja por terra e não encontra rinocerontes nem tigres./ Entra no exército e não usa armadura./ Os rinocerontes não têm onde enfiar o seu chifre,/ Os tigres não têm onde fincar as suas garras,/ As armas não têm onde enfiar a sua lâmina./ Por que razão?/ Porque não tem sepultura. (LAO TSE, 2010, p. 151)}

É um corpo que desconhece a morte, é um corpo que não morre. É "assim por si mesmo" (LAO TSE, 2010, p. 38), sem agitação, um sopro no vazio, feito de dois outros (físico e nuvem segundo o Tao), que dá vida aos corpos e "sabe conservar a vida".

Entre o antes e o depois, entre dois limites, fazem-se exercícios respiratórios. Respirar, sentindo-o intensamente, é uma força plena que apanha essas outras forças imperceptíveis. E nesse movimento partimos, partimos desse corpo que não nos convém. Saímos atentos, a andar ou sentados, ou de pé, torcidos ou deitados, distendidos ou contraídos. A falar ou em silêncio, o que quer que estejamos a fazer. No instante mesmo, fluímos num mesmo, e noutros corpos, simultaneamente. No "momento presente", retornamos outros, entramos ou estamos de chegada, encarnamos ou incorporamos todas as partículas elementares do cosmos.

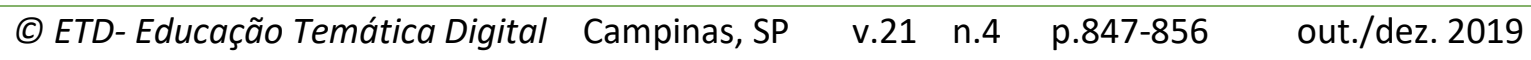




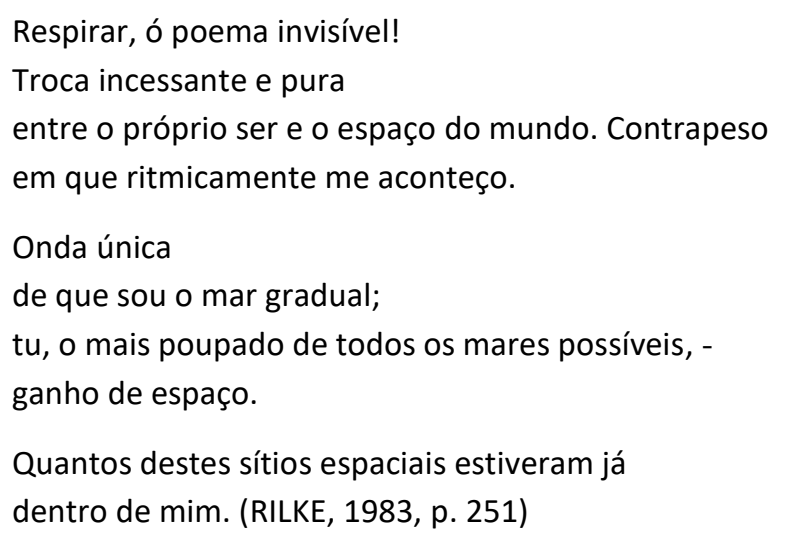

$\mathrm{O}$ ar que circula no corpo e, entre ele e o espaço do mundo - lugar de acontecimentos invisíveis - abre um espaço intervalar no tempo, no espaço claro. Ar como atmosfera numa onda única de tempo, que une mar e céu. Nesse corpo, que se escapou, metamorfoses vêm e transpõem o transitório sem cessar. Curvas de voo no ar, sem vestígio, sem pisadas, devêm vento, num mar gradual, numa troca incessante no espaço, e diz Rilke ainda: "E se o mundo se esqueceu de ti, vê/ se à Terra muda e calma dizes: - Corro./ E diz à água rápida: - Não morro" (RILKE, 1983, p. 264).

Uma outra respiração e um outro corpo também ele liberto da morte. A abertura, potência imperceptível que não morre é capaz de criar e mudar mundos inteiros. Um Caos verdadeiro (Paul Klee) sem peso e sem medida, "spissitudo spiritalis" (MALDINEY, 1973, p. 184). "Sob esta fina chuva respiro... Germinamos. [...] Onde tudo é denso e fluido ao mesmo tempo, natural” (DORAN, 1978, p. 112-113).

E o corpo surge "gracioso ou glorioso, para atingir finalmente o desaparecimento do corpo visível" (DELEUZE, 1985, p. 244). Um corpo que é um caos-germe do qual sai qualquer coisa, um ritmo, e por ele mesmo sai luz, uma presença. Do pássaro que pousa no campo sai o guarda-chuva de Bacon.

Produzir vazio para antecipar o devir. Iniciar o processo de criação é um acontecimento vital que implica uma relação de tensão imperceptível com um futuro e um espaço e é um encontro, não é uma construção, é alguma coisa que passa ou que se passa entre-dois. Assim:

Não são os deuses que são encontrados; mesmo ocultos, os deuses não passam de formas para a recognição. O que é encontrado são os demónios, potências do salto, do intervalo, do intensivo ou do instante, e que só preenchem a diferença com o diferente. (DELEUZE, 1992, p. 248)

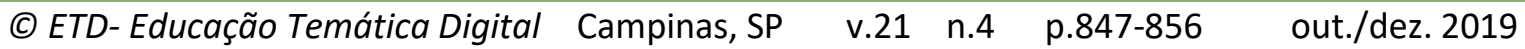


Até chegar ao vazio onde se pode fazer como Bacon faz: "uma espécie de declaração de fé na vida" (DELEUZE, 2011, p. 118). "Fé na vida" é uma maneira de dizer o que acontece num encontro desse tipo. Uma possibilidade de fazer nascer a sensibilidade no sentido, "assim por si mesmo" com incontáveis "sítios espaciais" que nos atravessam e são fonte de força, coma a força é fonte de transformação.

No final de $O$ que é a filosofia? (DELEUZE, 1992, p. 185-186), diz-se que alma, ou força tomada no sentido de Leibniz, não faz nada nem age, mas está apenas presente, conserva. Existe pois em nós uma alma, que é uma força que conserva. Um tipo de ligação animado de vida própria, vazio que é vazio. "A alma como vida dos fluxos é querer-viver, luta e combate" (DELEUZE, 2000, p. 72) que conserva e compõe e é ela que responde ao caos destruidor. Força de sentir que traz e transfere os materiais e os elementos mais complexos, todas as variedades do universo que compõem o plano da vida.

Voltamos a Rilke: se o mundo se esqueceu de ti, vê e diz: Corro e não morro.

Um certo corpo insiste e resiste, respira. Um corpo em devir. Vazio pleno, rítmico. No instante breve em que, simultaneamente, o espírito se faz espaço e se alarga e o tempo se alonga. Faz-se um corpo no momento presente, em tempo real, de uma única vez. Um corpo cósmico. Faz-se um corpo que escapa às dicotomias, aos poderes, às hierarquias, à percepção habitual. Com outros órgãos, sem órgãos, numa relação íntima com a vida. Um corpo que guarda vazios suficientes para permitir que neles saltem cavalos. Terminamos com Bergson:

Como turbilhões de poeira levantados pelo vento que passa, os vivos giram sobre si mesmos, suspensos pelo grande sopro da vida. São portanto relativamente estáveis, e falsificam tão bem a imobilidade que os tratamos mais como coisas do que como progressos, esquecendo que a própria permanência da sua forma não é mais do que o desenho de um movimento. Por vezes, no entanto, materializa-se diante dos nossos olhos, numa fugidia aparição, o sopro invisível que os carrega. Temos essa súbita iluminação diante de certas formas de amor maternal, tão impressionante, tão tocante também na maior parte dos animais, observável até na solicitude da planta pela sua semente. Esse amor, no qual alguns viram o grande mistério da vida, talvez nos revelasse o seu segredo. Mostra-nos cada geração debruçada sobre a que se irá seguir. Deixa-nos entrever que o ser vivo é sobretudo um lugar de passagem e que o essencial da vida reside no movimento que a transmite. (BERGSON, 1959, p. 603)

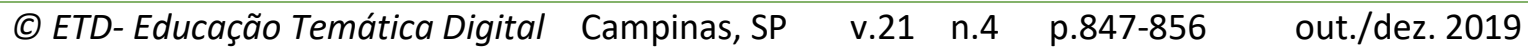




\section{REFERÊNCIAS}

BERGSON, Henry. Cuvres. Paris: PUF, 1959.

BRÉHIER, Émile. La théorie des incorporels dans l’ancien stoicisme. Paris : Vrin, 1997.

CHENG, François. Le vide et le plein. Le langage pictural chinois. Paris: Seuil, 1979.

DELEUZE, Gilles, Logique du sens. Paris: Minuit, 1969.

DELEUZE, Gilles. Cinéma 1. l'image-mouvement. Paris: Minuit, 1983.

DELEUZE, Gilles. L'image-temps. Paris: Minuit, 1985.

DELEUZE, Gilles. Francis Bacon: lógica da sensação. Tradução de Miranda Justo. Lisboa: Ed. Orfeu Negro, 2011.

DELEUZE, Gilles; GUATTARI, Felix. Mille plateaux. Paris: Minuit, 1980.

DORAN, Michael (Org.). Conversations avec Cezanne. Paris: Ed. Macula, 1978.

DUCHAMP, Marcel. Duchamp du signe. Écrits. Paris: Ed. M. Sanouillet : E. Peterson, Flammarion, 1975.

LAO TSE. Tao te king, livro do caminho do bom caminhar. Tradução de António Miguel de Campos. Lisboa: Relógio d'Água, 2010.

MALDINEY, Henry. Regard parole espace. Lausanne: Ed. L'Age d'Homme, 1973.

MALDINEY, Henry. Art et existence. Paris: Klincksieck, 1985.

RILKE, Rainer Maria. Os cadernos de Malte Laurids Brigge. Tradução de Paulo Quintela. Porto: O Oiro do Dia, 1983.

Revisão gramatical realizada por:

Ricardo Magno Macedo Argolo.

Email: magno.argolo@hotmail.com 